\title{
Increasing the reliability of engineering buildings and strengths of use of new small- based equipment for concrete works
}

\author{
Inga Emeljanova $^{1}$, Mykola Derevyanko ${ }^{1}$, Sergiy Guzenko ${ }^{1}$, Denys Chayka ${ }^{1,{ }^{*}}$ and Dmytro \\ Subota ${ }^{1}$ \\ ${ }^{1}$ Kharkiv National University of Civil Engineering and Architecture, Sumska st. 40, 61002 Kharkov, \\ Ukraine
}

\begin{abstract}
The article considers the possibility to increase the reliability of engineering buildings and facilities due to the use of new small-based equipment both in the operating conditions of technological complexes and in the conditions of technological sets. An example of the use of a technological complex with a universal hose concrete pump for strengthening the supporting columns of a medical centre being built by the wet concrete spraying method is given. The structural scheme of energy consumption by technological sets of small-based equipment is given. The variants of using the technological set of small-sized equipment for concrete work in various ways. One of the universal technological kits of effective small-based equipment is shown. As part of the proposed kit, the base machine can successfully be used universal non-piston hose concrete pump. Dependencies for determining the productivity of a hose concrete pump and the cost of its power for transporting a concrete mixture are proposed.
\end{abstract}

\section{Introduction}

Up-to-date construction assumes various types of equipment which are used as separate machines $[1-5]$ when performing concrete works. A rational solution in the performance of concrete work in the construction site [6] is the use of certain types of equipment in both technological complexes and technological kits.

Technological complexes consist of separate types of machines (equipment), which consistently perform operations of the technological cycle in the manufacture of reinforced concrete structures or the erection of buildings or structures from monolithic reinforced concrete directly in the construction site.

Considering the concreting processes under such conditions [7, 8], a new universal small-based equipment, which is patented in Ukraine [9], attracts attention and passed approbation at many construction sites when performing works by the wet concrete spraying method.

New small-based equipment that works in the conditions of technological complexes or kits includes the following:

- concrete mixers operating in a cascade mode (trivalent and gravity-forced action);

- mortar-concrete pumps (with ball and poppet valves);

- concrete pumps (universal non-piston hose);

- robotic nozzles for concrete spraying method with a ring nozzle.

\footnotetext{
* Corresponding author: d.chayka93@.gmail.com
} 
One of the factors determining the efficiency of small-based equipment is its energy consumption. The completeness of a particular technological complex or kits in the conditions of a construction site, first of all, should ensure its operation with minimal energy consumption in the presence of a basic machine.

One of the last facilities, where the efficiency of the technological complex with the new equipment mentioned above was confirmed, is the construction of the medical center "OnClinic" (Kharkov).

Shotcrete works were carried out according to the technological scheme shown in Fig. 1.

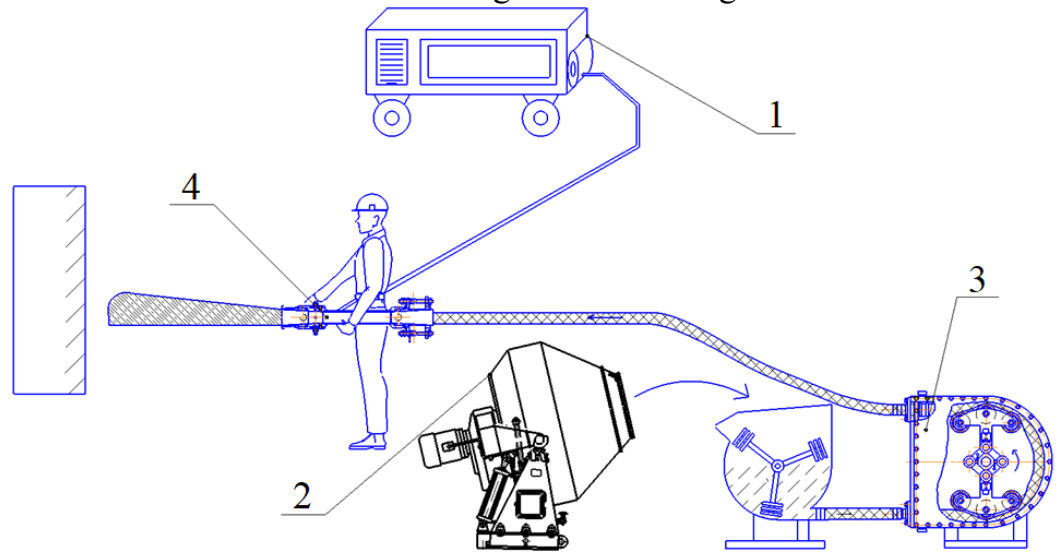

Fig. 1. Technological scheme of performance of concrete gun works by wet method when using a complex of small-based equipment with universal non-piston hose concrete pump. 1 - compressor mobile installation; 2 - gravitational concrete mixer; 3 - non-piston hose concrete pump; 4 - gunned nozzle with a ring nozzle.

The basic machine in this complex is a non-piston hose concrete pump which is shown below on the construction site of the medical centre "OnClinic".

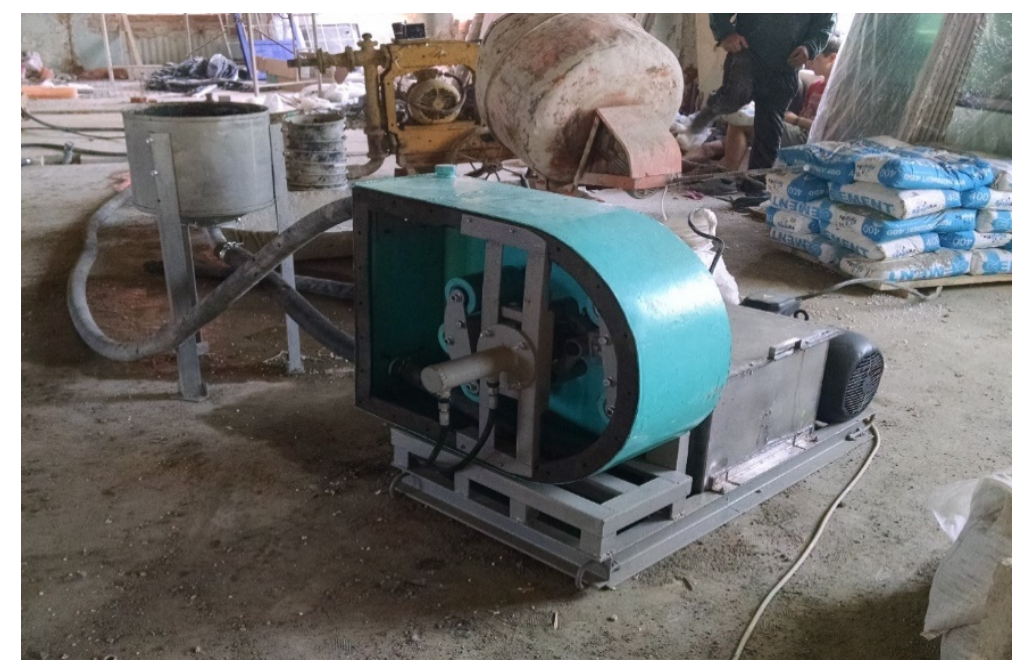

Fig. 2. Universal non-piston hose concrete pump with hydraulic drive on the territory of the "OnClinic" medical centre under construction.

According to the method of wet concrete spraying, the supporting columns of the building were reinforced. At the same time, the following consumption of constituents per $1 \mathrm{~m}^{3}$ of concrete was used: sand $-640 \mathrm{~kg}$, cement $-340 \mathrm{~kg}$, crushed stone of fraction 
up to $5 \mathrm{~mm}-1240 \mathrm{~kg}$, water -1701 . Polypropylene fiber $-1.5 \%$ (fiber length $1=12 \mathrm{~mm}$ ); plasticizer Sika plus Mix $-0.2 \%$.

Figure 3 shows the process of reinforcing columns using a nozzle with a ring nozzle. It is seen that the nozzle also produces a concentrated jet of concrete mixture practically without rebound.

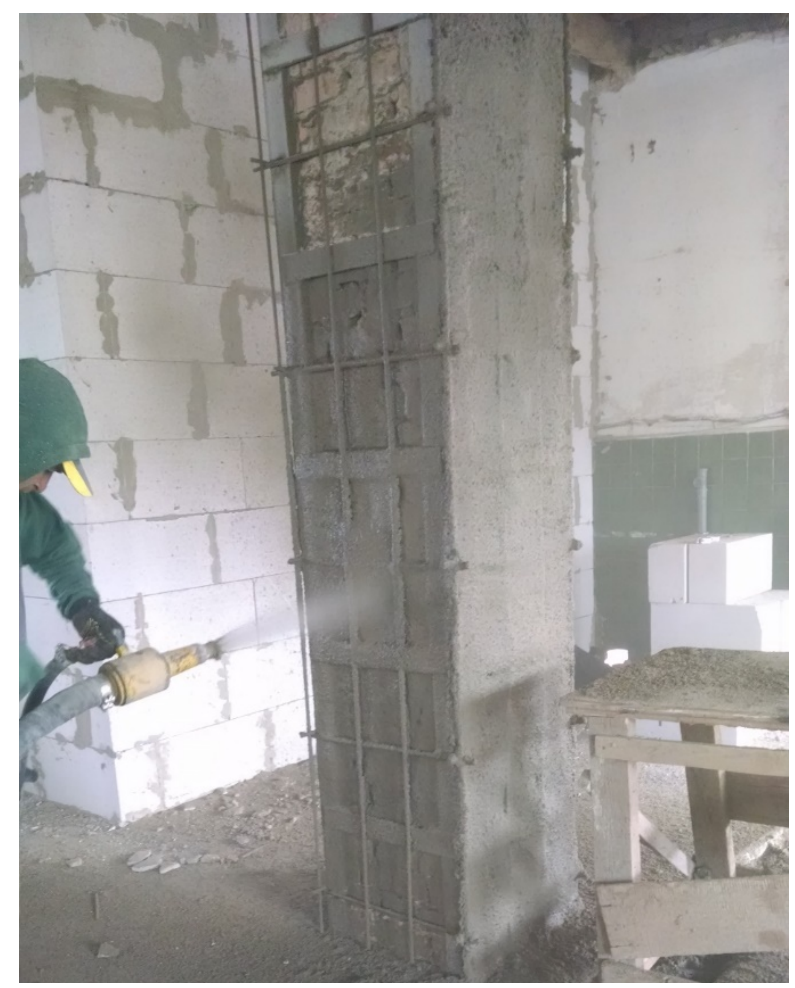

Fig. 3. Strengthening of the column during concreting by the wet concrete spraying method.

More rational is the use of small-based equipment in the conditions of the technological kit.

The structural scheme of energy consumption by technological kits of small-based equipment is shown in Fig. 4 [10].

The technological kit has a common frame on which certain types of equipment are mounted, which are independent modules, which, when performing concrete works, allow all operations of the cycle to be combined in time.

It can be considered that the technological kits are assembled from separate modules, which are machines (equipment) presented in this scheme. Each of the modules is characterized by separate capabilities that are used in specific construction conditions [11].

The use of such modular kits for the manufacture of reinforced concrete structures and products in the construction site using the method of off-shuttering concreting is of particular use.

Thus, new small-based equipment in various combinations in the form of modules can effectively work as part of universal technological kits and be used for various types of works. For example, for:

- performing spray-concrete works using the wet concrete spraying method: "metering unit $\rightarrow$ concrete mixer operating in cascade mode $\rightarrow$ two-piston or hose-type concrete pump $\rightarrow$ working nozzle with annular nozzle $\rightarrow$ concreting surface".

- off-shuttering concreting by wet concrete spraying using fibrous concrete mixtures for the manufacture of reinforced concrete structures of complex geometric shapes: "Fiber 


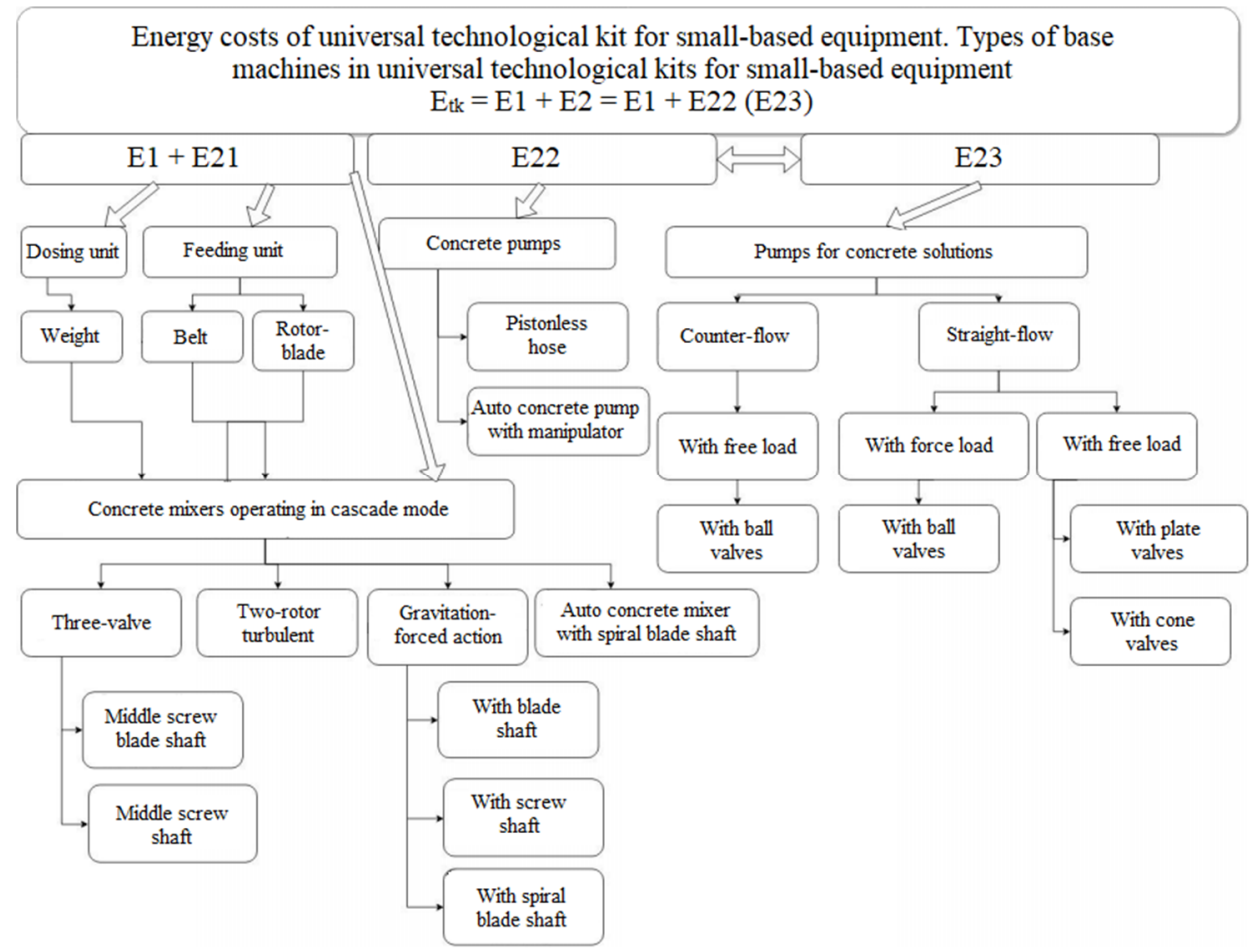

Fig. 4. Structural scheme for determining the power costs of a universal technological kit of smallbased equipment for the conditions of the construction site.

automatic cutter $\rightarrow$ dosing unit for concrete mix components $\rightarrow$ three-shaft concrete mixer $\rightarrow$ non-piston hose concrete pump $\rightarrow$ concrete spraying nozzle with ring nozzle $\rightarrow$ concrete frame with embedded structures details".

Fig. 5 shows one of the universal technological kits of effective small-based equipment.

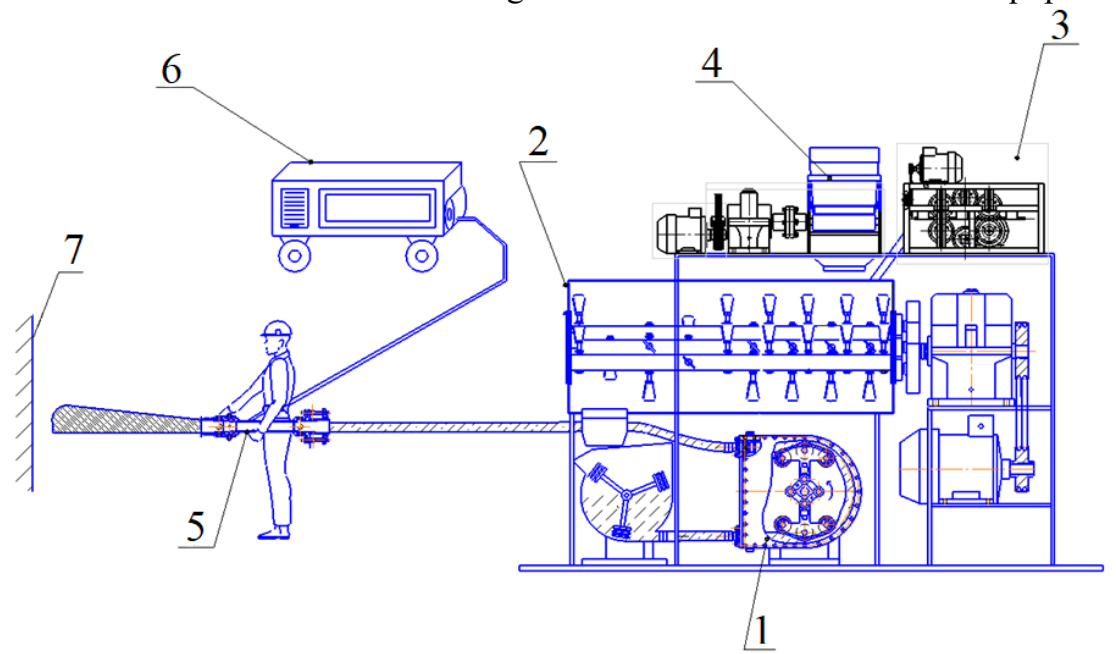

Fig. 5. Universal technological kit for small-based equipment with a pistonless hose concrete pump. 1 - universal pistonless hose concrete pump; 2 -three-shaft concrete mixer; 3 - machine-cutter of fiber; 4 - belt feeder; 5 - concrete spraying nozzle with a ring nozzle; 6 - mobile compressor unit; 7 - concrete spraying surface. 
Basic concrete pump with hydraulic drive, in comparison with two-piston concrete pumps, has a number of advantages: minimum weight with a wide range of performance, reliability of construction and improved operating conditions due to the improvement of its design in comparison with existing hose concrete pumps, economic energy consumption.

\section{Theoretical part}

Performance of a hose concrete pump which, as a basic machine, determines the productivity of the entire technological kit is defined as [12]:

$$
\Pi_{\text {tech }}=3600 \cdot F_{\text {hose }} \cdot v_{a v} \cdot k_{1} \cdot k_{2} \cdot k_{3}
$$

where, $F_{\text {hose }}$ - cross-sectional area of the hose in the concrete pump housing, $\mathrm{m}^{2}$; $v_{a v}$ - average speed of the concrete mixture through a flexible hose, $\mathrm{m} / \mathrm{s} ; k_{1}$ - coefficient that takes into account the gradual build up of the force created by the pinch rollers of the rotor when compressing the outside of the hose in the pump casing; $k_{2}$ - coefficient that takes into account the reliability of the hose in the pump casing, taking into account the ultimate stress state; $k_{3}$ - coefficient that takes into account the conditions for the mixture to be delivered by a concrete pump via a flexible hose, taking into account the presence of its reverse currents.

$$
\text { Coefficient } \quad k_{1}=\frac{G_{1}+G_{2}+G_{3}}{G_{1}+G_{3}},
$$

where, $G_{1}, G_{2}, G_{3}$ - respectively, the weight of the concrete mixture resisting the influence of the lateral and central rollers of the rotor on the outer surface of the deformable hose, through which the mixture is fed into the transport main.

Coefficient

$$
k_{2}=\frac{\sigma_{e q}}{[\sigma]_{g}},
$$

where, $\sigma_{e q}$ - total all-round voltage that the hose in the concrete pump casing undergoes as the next portion of the concrete mix moves under it under the action of the pinch rollers of the rotor, $\mathrm{MPa} ;[\sigma]_{g}$ - allowable stress on hose breakage, MPa.

Coefficient

$$
k_{3}=\frac{m_{\text {outl }}}{m_{\text {inl }}}
$$

where, $m_{\text {outl }}$ - weight of concrete mixture at the outlet of the working part of the concrete pump hose; $m_{i n l}-$ weight of the concrete mixture that enters the concrete pump from the hopper.

The following dependence can be used to determine the cost of power universal hose concrete pump:

$$
P_{d r}=k_{p . r} \cdot \prod_{t e c h} \cdot \rho_{0 c . p} \cdot v_{a v}^{2} / 1000 \cdot \eta_{g e n},
$$


where, $k_{p . r}$ - coefficient that takes into account the power reserve for overcoming resistance to movement of the mixture through the pipeline; $\rho_{0 c . p}-$ average density of transported concrete mix; $\eta_{\text {gen }}-$ overall efficiency of the concrete pump.

If there is a gradual loading of the hose in the working part of the pump casing with the rotating rotor rolls $[13,14]$, the service life of the new machine exceeds the life of the hours of modern hose-type concrete pumps by $25 \%$.

Thus, technological sets of small-sized equipment with a new universal hose concrete pump allow us to carry out concrete work in the construction of reliable engineering buildings and structures in stable construction conditions.

\section{Conclusions}

1. The list of new equipment protected by patents of Ukraine is given which can be used as separate modules of universal technological complexes and sets of small-sized equipment for construction site conditions.

2. The use of a non-piston hose concrete pump of a new constructive solution is shown with the reinforcement of support columns by the wet concrete spraying method, the medical centre under construction.

3. The structural scheme of energy consumption by technological sets of small-sized equipment is given.

4. One of the universal technological kits of effective small-sized equipment is shown.

\section{References}

1. S. Moran, Process plant layout (Chapter 25), 369-376 (2017)

2. M. C. Valigi, I. Gasperini, Simulation Modelling Practice and Theory, 15 (10), 1211-1223, (2007)

3. J. Henikl, W. Kemmetmiller, A. Kugi, Automation in Construction, 61, 112-123, (2016)

4. J. Klespitz, L. Kovács. SAMI 2014, IEEE 12th international symposium on applied machine intelligence and informatics, 191-194, (2014).

5. A. Daszczenko J. Glinski, E. Krasowski, et al., Hydraulika: Maszyny hydraulicznu. 385, (2010).

6. S. A. Hamid, A. Nouh, N. Y. Zabel, HBRC Journal, (2017).

7. Ö. Sjöström, Storage in Excavated Rock Caverns: Rockstore 77, 585-591, (1978)

8. J. Wang, D. Niu, Y. Zhang, Construction and Building Materials, 95. 312-328, (2015)

9. I.A. Emeljanova, A.A. Zadorozhny, S.A. Guzenko, N.A. Melentsov. Two-piston mortarconcrete pumps for construction site conditions, (Kharkov: Timchenko AN), 196, (2011)

10. I.A. Emeljanova, V.V. Blazhko, A.I. Anischenko, Scientific Bulletin of Civil Engineering 91 (1), 238-243, (2018)

11. I.A.Emeljanova, D.O. Chayka, D.S. Kabanets Utilities of cities, 137, 98-103, (2017)

12. I. Emeljanova, V. Virchenko, D. Chayka, IJET, 7(3,2), 97-101 (2018)

13. D. Chayka, I. Emeljanova, A. Grigoryev, P. Andrenko, IJERA, 38, 46-59, (2018)

14. I. Emeljanova, V. Blazhko, V. Shatobhin, D. Chayka, D. Kabanets, Scientific Bulletin of Civil Engineering, 90 (4), 136-145, (2017) 